\title{
Consensus science, or consensus politics?
}

\author{
To some, the Intergovernmental Panel on Climate Change represents the
} pinnacle of scientific collaboration. To others, it is a victory for politics over science. Mark Schrope talks to the experts debating our planet's future.
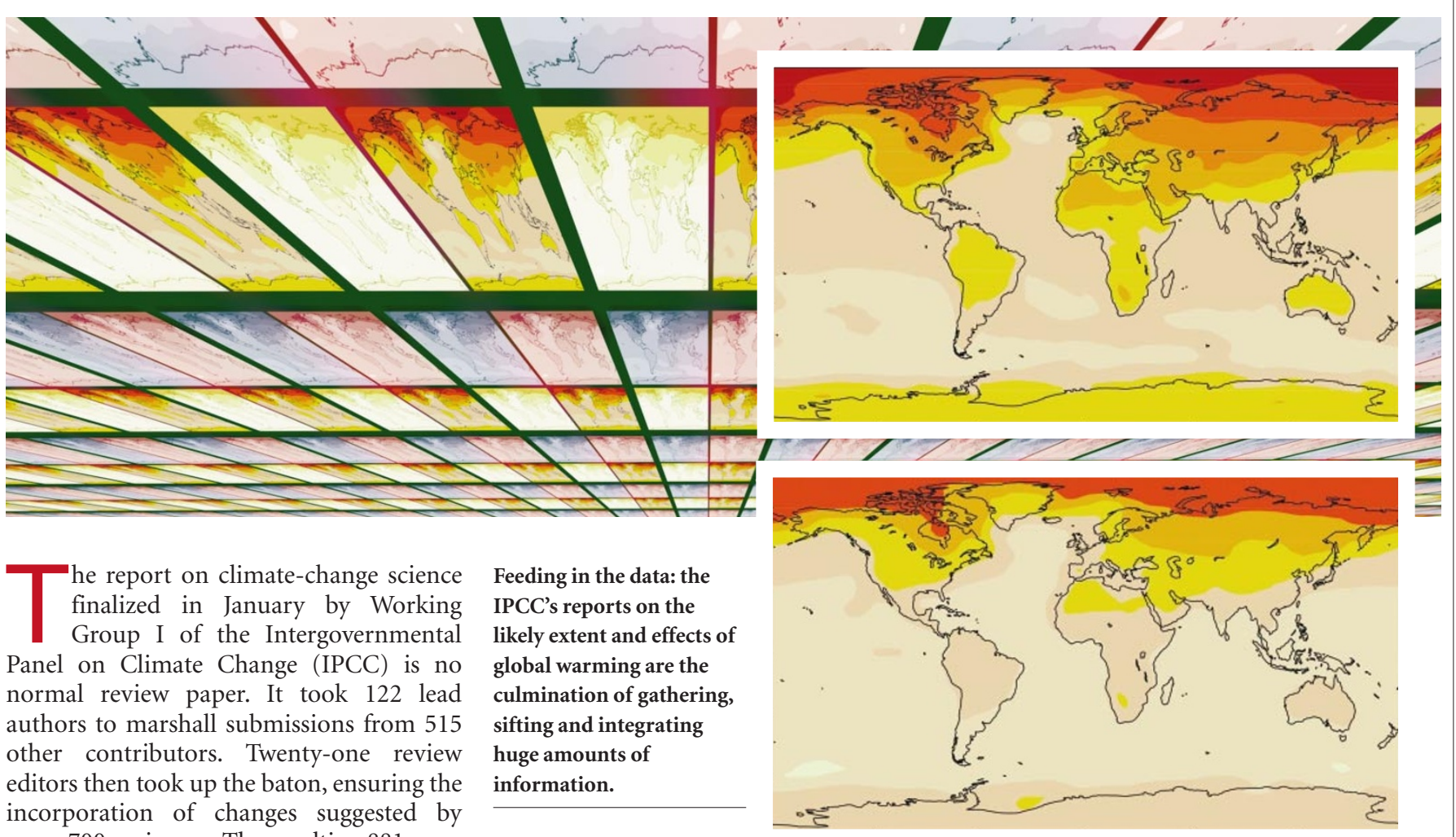

$\mathrm{T}$ he report on climate-change science finalized in January by Working Group I of the Intergovernmental Panel on Climate Change (IPCC) is no normal review paper. It took 122 lead authors to marshall submissions from 515 other contributors. Twenty-one review editors then took up the baton, ensuring the incorporation of changes suggested by some 700 reviewers. The resulting 881-page document took three years to produce.

Rarely does a single scientific document have such far-reaching consequences for international politics. The report - together with two companions produced by the IPCC's other working groups, dealing with the consequences of climate change and strategies for mitigating them - will be a key reference for delegates who meet in Bonn next week in an attempt to revive the Kyoto Protocol on limiting greenhouse-gas emissions.

Most experts view the IPCC's reports as a huge success story - the first serious attempt to reach a global consensus on a complex scientific issue. But others claim that the involvement of government officials in writing the vital summaries for the reports undermines normal scientific peer-review procedures. Some critics even allege that climate researchers have themselves skewed the reports by expressing their own environmentalist views.

Whatever the truth, such criticisms cannot be ignored. The IPCC aims to provide information to policy-makers without endorsing specific policies. As such, it can only work if it is widely perceived to represent a highly credible and unbiased consensus.

Feeding in the data: the IPCC's reports on the likely extent and effects of global warming are the culmination of gathering, sifting and integrating huge amounts of information.

This year's series of reports was the IPCC's third comprehensive assessment of climate change since it was established in 1988. The arduous process of producing an assessment begins with the assembly of a team of authors for each working group. Ensuring wide international participation is important, because climate change means different things to different countries. A small-island state that risks flooding if sea levels rise may not see eyeto-eye with an oil-exporting nation, for instance. So the IPCC Bureau, the panel's governing body of 30 leading climate experts, invites every one of almost 200 eligible countries to nominate individuals for the working groups. The bureau then makes the final choice so that the lead authors reflect an appropriate international selection while having strong scientific credentials.

\section{Data detectives}

The authors then start combing the literature for important papers, and calling on other scientists to submit research that is awaiting peer review or publication. They face the Herculean task of condensing the hundreds of individual submissions into a single report - the inclusion of important new findings continues almost right up to the final deadline.

The working groups' draft reports are reviewed by a second team of experts appointed by the bureau. Individual countries also have a chance to comment - the first, but not the most controversial, opportunity for politicians to influence the report. For the first and second IPCC assessments, the authors were left to incorporate these revisions. But after complaints that some suggestions were not adequately taken on board, whereas other changes were not reviewed by the original authors, this time a third body of scientific experts - the review editors - was appointed by the bureau to oversee the revision process.

Given the reports' size - the third full assessment covers about 2,500 pages - few people ever read a full working-group report, much less an entire assessment. Instead, most rely on the 'Summary for Policymakers' (SPM) that accompanies each working-group report. For many critics of the IPCC process, the SPMs, and the way in which they are interpreted in the media, are the key problem.

Drafting an SPM is extremely difficult. When circulated for comment, the draft 
SPM for Working Group I's third assessment attracted roughly 20 words of comment for every word of the original. Once these comments have been incorporated, the fun really begins. Each working group's SPM has to be approved by a special plenary meeting. This time, roughly 50 authors attended each plenary, along with representatives from nongovernmental organizations (NGOs) - but both the scientists and NGOs are there only to advise. The final word rests with 400-odd delegates from the participating countries, who may or may not have a strong background in a relevant scientific discipline.

\section{A literary circus}

Every word has to be agreed on unanimously before it enters the SPM. With discussions translated simultaneously into five different languages, the approval of Working Group I's summary for the third assessment — originally just seven pages long — took four days. By the time the delegates to the plenary, held in Shanghai in January, had finished, the document had more than doubled in length.

"You've got an almost circus-like atmosphere," says Thomas Karl, director of the National Climatic Data Center in Asheville, North Carolina, and a Working Group I lead author who was present in Shanghai. "It's hard...very hard."

As government representatives, delegates may arrive with goals for what the summary should say that are based on policy objectives rather than science. "They are trying to perhaps weight certain things based on their national interests," says Cynthia Rosenzweig, a Working Group II lead author who heads the Climate Impacts Group at NASA's Goddard Institute for Space Studies in New York.

Kevin Trenberth, an atmospheric scientist at the National Center for Atmospheric Research in Boulder, Colorado, and a lead author for Working Group I, says that the wrangling in Shanghai began with the first paragraph. Saudi Arabian delegates, whom

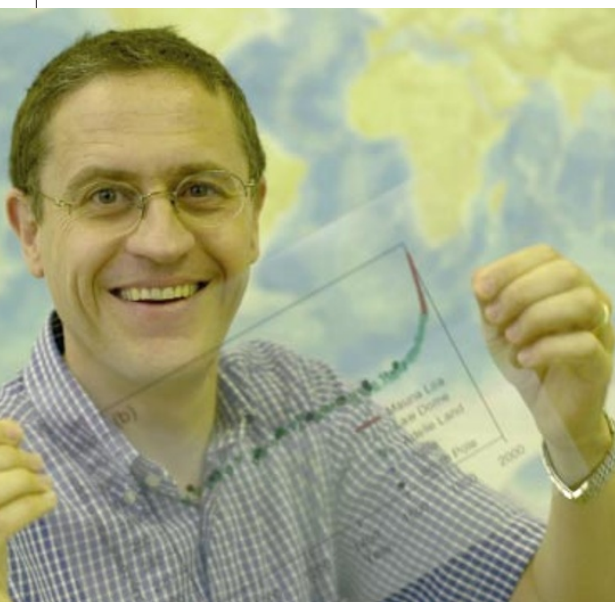

No doubt: Thomas Stocker feels that the IPCC's reports make clear any uncertainties. some allege are keen to play down the threat of global warming to protect their country's oil exports, objected to a sentence that read: "Many hundreds of scientists contributed to its preparation and review." The Saudis felt this implied that all of these scientists endorsed the report in every respect. After some verbal wrestling, the line was altered to read: "Many hundreds of scientists from many countries participated in its preparations and review." In the days of discussion that followed, says Trenberth, the process was repeated over and over again.

The most difficult negotiations, according to Trenberth, related to the connection between human activity and climate change. One contentious line began as: "Despite these uncertainties, it is likely that increasing concentrations of anthropogenic greenhouse gases have combined substantially to the observed warming over the last 50 years." By the end of the plenary, it had become: "In the light of new evidence and taking into account the remaining uncertainties, most of the observed warming over the last 50 years is likely to have been due to the increase in greenhouse gas concentrations."

To the untutored eye, these slight differences in wording may seem of little significance. And to Rosenzweig, the fact that such protracted negotiations result in relatively limited changes is a testament to the quality of the IPCC scientists' work. By defining the scientific consensus between narrow limits, she argues, there is little room for bias in the summary. Rosenzweig says the biggest problem was coping with scientists pushing to have their own results included.

Indeed, despite the unusual nature of a process that involves political appointees agreeing on how a scientific study should be summarized, most of the IPCC's authors are satisfied with the way it works. But many say that the SPMs should be marked to indicate that they are not solely the work of scientists. Robert Watson, director for the environment at the World Bank and chair of the IPCC Bureau, says he would not object to some words of explanation being included.

\section{Clarity or bias?}

John Houghton of Britain's Hadley Centre for Climate Prediction and Research in Bracknell, west of London, and co-chair of Working Group I, believes the plenary meetings actually improve the final SPMs. "It's more clear and more relevant," he says. "You might think it would make it worse, but it doesn't."

But speak to critics outside the IPCC's fold and you hear a different story. Fred Singer is a long-standing sceptic of the threat posed by global warming, and president of the Science and Environmental Policy Project, a pressure group in Arlington, Virginia. Singer thinks the main reports are sound, but he argues that the SPMs fail to

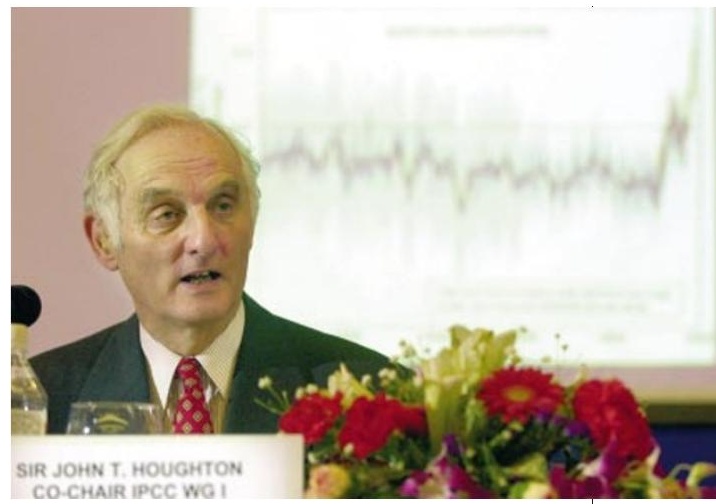

Up for discussion: John Houghton believes the plenary sessions improve the final report.

adequately acknowledge the uncertainties in climate-change science. According to Singer, the process that gives rise to the SPMs plays down uncertainties so as to force governments to take climate change seriously. "It is selective in the facts that it uses from the report," says Singer. "It slants things. It puts a spin on things. It starts out with a given conclusion and then selects those facts which support that conclusion."

Most climate researchers argue these charges should be laid at the door of Singer's group, not the IPCC. Thomas Stocker, a climate modeller at the University of Bern in Switzerland and one of Working Group I's lead authors, takes serious issue with Singer's broadside. "That's completely unfounded," he says. "If you read our SPM you will find plenty of sentences that explicitly state where there are uncertainties." He views the agreement between the full report and its précis in the SPM as impressive.

\section{Reflected glory}

Exactly how accurately the SPMs reflect the underlying reports was investigated last month by the US National Academy of Sciences (NAS) as part of a request from President George W. Bush to examine climate-change research (see Nature 411, $725 ; 2001)$. The NAS report focused on Working Group I - the most contentious, as the other two working groups depend in large part on its conclusions. Like the working group itself, the NAS report provided ammunition for both supporters and critics of the IPCC. Working Group I's SPM, concluded the NAS, is "consistent with the main body of the report". But the NAS report agreed that the SPM had failed to explain adequately the caveats on which some of the uncertainties it referred to were based.

"We found some understatements of uncertainties, but generally changes made from the technical chapters to the SPM didn't affect the impact of the statements very much, which was very impressive," says Ralph Cicerone, an atmospheric scientist and chancellor of the University of California, Irvine, who chaired the NAS panel. Cicerone adds 
that his panel conducted a quick survey of IPCC authors in the United States and found that those who responded said unanimously that the SPM accurately represented what they wrote in the main text.

But Richard Lindzen, a meteorologist at the Massachusetts Institute of Technology and an author of the NAS report, does not see it the same way. "Within the confines of professional courtesy," Lindzen wrote in an opinion piece in The New York Times, "the panel essentially concluded that the IPCC's Summary for Policymakers does not provide suitable guidance for the US government." Lindzen has long argued that evidence for climate change is too shaky to justify the costly strategies mooted to tackle it.

Some critics of the IPCC believe that removing politicians from the process could be one way of ending the arguments. "Let the scientists tell the world what the scientists said," says Robert Balling, director of the Office of Climatology at Arizona State
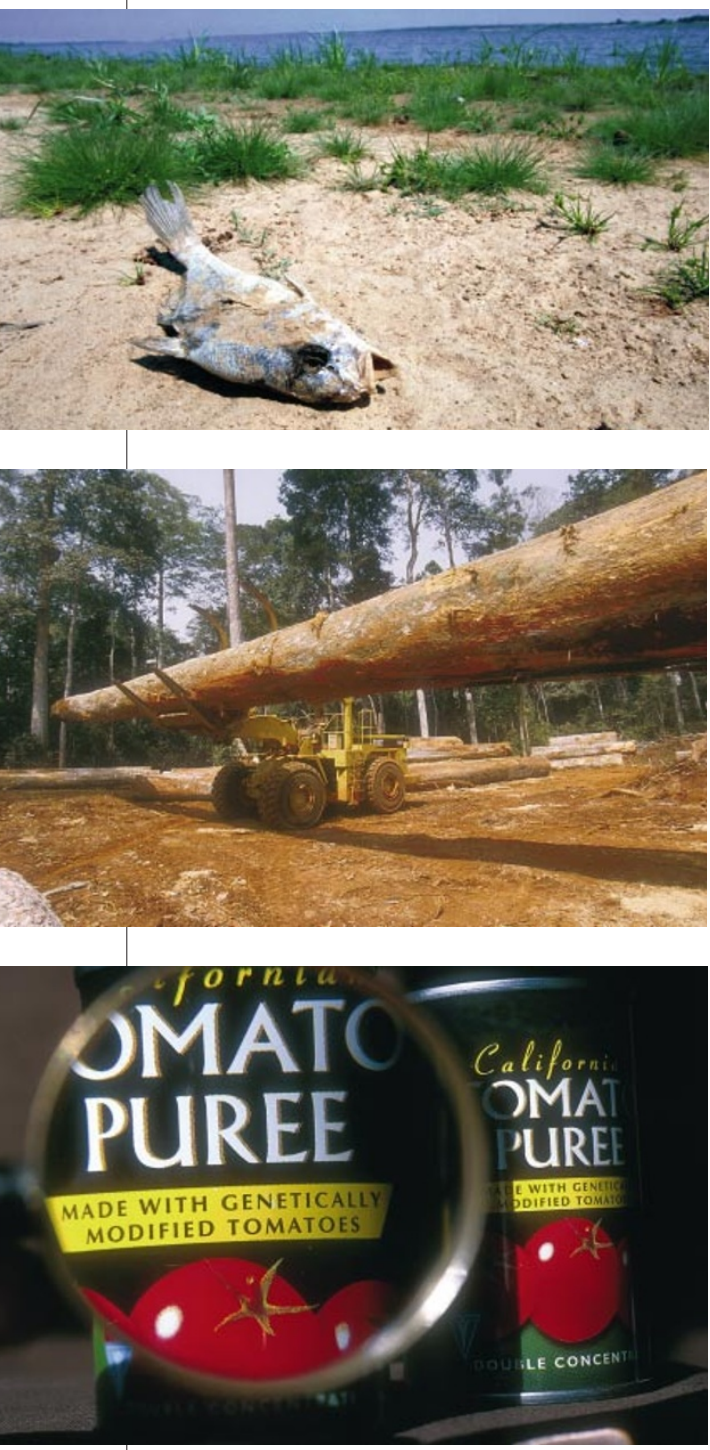

Under review: could an IPCC-style approach help assessments of lack of water in developing countries, deforestation or genetic modification? t might look like a

circus at times, but a global response to climate change would probably be impossible without the IPCC.

University in Tempe. Although Balling contributed material to the Working Group II report, he is a prominent global-warming sceptic and a vocal critic of the IPCC.

But most participants in the IPCC process believe that the presence of national delegates is crucial. "If you didn't have that then the report wouldn't be so important. It's as simple as that," says Michael Grubb, an energy economist at Imperial College London and a Working Group III lead author. He argues that involving government officials in the IPCC process forces politicians to take a close look at the report and the underlying science, rather than simply putting it on the shelf.

Michael Oppenheimer, chief scientist with the New York-based NGO Environmental Defense, and a lead author for Working Group I, agrees. "If the price paid to get there is some discomfort among some of the players and criticism because it's not purely a product of scientists, I think that's a price worth paying," he says.

\section{Panel beating}

In the past, revisions to the working groups' full reports subsequent to SPM approval have caused problems. When substantial additions are made to the draft of the SPM, authors must sometimes supplement the main report to ensure that a given point is adequately covered. After the IPCC's second assessment was published, Singer's Science and Environmental Policy Project alleged that this process had proceeded largely unchecked, with some authors adding material to the main report without giving others the chance to comment. To deflect such criticism of the third assessment, every change to the main report was logged, whether it resulted from the formal review process or the plenary sessions.

Some critics allege that problems of bias lie not with the SPMs or the IPCC process, but with the climate research community as a whole. They argue that many climate scientists hold environmentalist views, and so tend to stress the importance of research that paints the most worrying picture of climate change in order to spur politicians into action.

The Global Climate Coalition (GCC), based in Washington, which styles itself as a "voice for business in the climate debate", draws attention to remarks made by Stephen Schneider, a climate-change researcher at
Stanford University in California and a lead author of the Working Group II report.

In a 1989 Discover magazine article, Schneider discussed the dilemma facing scientists who wanted to draw attention to climate change while remaining true to current scientific knowledge of the subject. "We need to capture the public's imagination," he noted. "That entails getting loads of media coverage, so we have to offer up scary scenarios, make simplified and dramatic statements and make little mention of any doubts we might have." Although Schneider went on to say that he hoped climatologists could be both effective and honest, the remarks were seized on by bodies such as the GCC as evidence that scientists were exaggerating the consequences of climate change.

\section{Tempered view}

John Christy, an atmospheric scientist at the University of Alabama in Huntsville, and a lead author for Working Group I, believes that researchers who are new to climatology, many of whom have been attracted to the field because of its 'green' associations, are more likely to back extreme climatechange predictions. But he argues that they are largely countered by more experienced researchers who tend to make more conservative judgements because they place less stock in the long-range climate forecasts.

The fact that the IPCC's consensus is backed by Christy, whose views on climate change have on occasion provided ammunition for global-warming sceptics, provides one indication that - despite its critics the organization is working effectively. But where the IPCC goes from here is still being debated. A fourth assessment will almost certainly take place, but Watson says it might focus on new information rather than attempt another full review.

Some researchers, meanwhile, suggest that the IPCC model should be applied to other thorny issues. Christy, for example, would like to see a similar effort devoted to the environmental problems threatening developing nations, such as deforestation and the lack of suitable fresh water. And the UK House of Commons' Science and Technology Committee recently suggested that the IPCC model could be applied to ocean pollution and genetic modification. "It's the only long-term successful example of how a complex scientific issue can be brought to the decision makers," says Stocker.

Whether or not the model is applied elsewhere, the fact that IPCC reports are accepted as the scientific guide for the Kyoto Protocol negotiations is, for many involved, proof enough that the process is working as well as can be hoped. It might look like a circus at times, but a global response to climate change would probably be impossible without it.

Mark Schrope is a freelance writer in Melbourne, Florida. http://www.ipcc.ch 